\title{
On-Farm Mitigation of Transmission of Tuberculosis from White-Tailed Deer to Cattle: Literature Review and Recommendations
}

\author{
W. David Walter, ${ }^{1,2}$ Charles W. Anderson, ${ }^{1,3}$ Rick Smith, ${ }^{4}$ Mike Vanderklok, ${ }^{4}$ \\ James J. Averill, ${ }^{4}$ and Kurt C. VerCauteren ${ }^{1}$ \\ ${ }^{1}$ National Wildlife Research Center, Animal and Plant Health Inspection Services, United States Department of Agriculture, \\ 4101 LaPorte Ave, Fort Collins, CO 80521, USA \\ ${ }^{2}$ US Geological Survey, Pennsylvania Cooperative Fish and Wildlife Research Unit, Pennsylvania State University, \\ 403 Forest Resources Building, University Park, PA 16802, USA \\ ${ }^{3}$ Missouri Department of Conservation, Resource Science Division, 551 Joe Jones Boulevard, West Plains, MO 65775, USA \\ ${ }^{4}$ Animal Industry Division, Michigan Department of Agriculture and Rural Development, Lansing, MI 48909, USA
}

Correspondence should be addressed to W. David Walter, wdwalter@psu.edu

Received 23 March 2012; Revised 16 July 2012; Accepted 17 July 2012

Academic Editor: Remo G. Lobetti

Copyright ( 2012 W. David Walter et al. This is an open access article distributed under the Creative Commons Attribution License, which permits unrestricted use, distribution, and reproduction in any medium, provided the original work is properly cited.

\begin{abstract}
The Animal Industry Division of the Michigan Department of Agriculture and Rural Development (MDARD) has been challenged with assisting farmers with modifying farm practices to reduce potential for exposure to Mycobacterium bovis from wildlife to cattle. The MDARD recommendations for on-farm risk mitigation practices were developed from experiences in the US, UK and Ireland and a review of the scientific literature. The objectives of our study were to review the present state of knowledge on $M$. bovis excretion, transmission, and survival in the environment and the interactions of wildlife and cattle with the intention of determining if the current recommendations by MDARD on farm practices are adequate and to identify additional changes to farm practices that may help to mitigate the risk of transmission. This review will provide agencies with a comprehensive summary of the scientific literature on mitigation of disease transmission between wildlife and cattle and to identify lacunae in published research.
\end{abstract}

\section{Introduction}

Bovine tuberculosis (TB) is an infectious disease caused by the bacterium, Mycobacterium bovis, that affects both domestic and wild animals worldwide. In Michigan, TB was discovered in free-ranging white-tailed deer (Odocoileus virginianus) following the 1994 firearm deer season [1] in portions of Alpena, Alcona, Oscoda, and Montmorency counties, now referred to as Michigan's TB core area. Between 1994 and 2010, 50 cattle (Bos taurus) farms have tested positive for TB in 7 counties, with 40 of the farms being beef and 10 being dairy. Although considerable deer reductions have occurred within Michigan's TB core area since 1994, new and recurring infections continue to plague Michigan farmers.

Wildlife reservoir hosts for M. bovis, other than whitetailed deer, include the brushtail possum (Trichosurus vulpecula) in New Zealand and European badger (Meles meles) in the United Kingdom [2-4]. Other wildlife that have been found infected with $M$. bovis in Michigan include elk (Cervus elaphus), coyote (Canis latrans), raccoon (Procyon lotor), black bear (Ursus americanus), bobcat (Lynx rufus), Virginia opossum (Didelphis virginiana), red fox (Vulpes vulpes), and domestic cat (Felis catus; $[5,6]$ ). Research examining transmission of M. bovis in Michigan has focused on deer-cattle interactions because of high deer densities and feeding practices that lead to deer congregating in high densities at feeding sites $[7,8]$. It is believed that if $M$. bovis were eliminated from deer then it would not be sustained in other wildlife species [9] and could be eradicated from cattle.

The Animal Industry Division of the Michigan Department of Agriculture and Rural Development (MDARD) created a Wildlife Risk Mitigation Action Project (WRMAP) 
to assist farmers with modifying farm practices to reduce potential for exposure to $M$. bovis from wildlife to cattle. The WRMAP recommendations are based on on-farm wildlife risk mitigation practices used elsewhere in the US $[9,10]$ and those in the UK $[11,12]$. Several farm practices that have been identified increase the risk of transmission of $M$. bovis such as livestock feed (e.g., hay, grain, and silage) storage, livestock access to daytime cover used by wildlife, and cattle access to standing water sources (e.g., swamps, ponds) commonly used by wildlife [13] and additional factors have been identified in the current review. For a detailed review of past and current M. bovis eradication efforts in Michigan and surveillance of white-tailed deer see Okafor et al. [14].

The objectives of this paper were to review the present state of knowledge of $M$. bovis excretion, transmission, and survival in the environment and the interactions of wildlife and cattle, with the intention of determining if the current recommendations by MDARD on farm practices are adequate and to identify additional changes to farm practices that may help to mitigate the risk of transmission. We used numerous databases (e.g., WorldCat, JSTOR, DigiTop, Web of Knowledge) in our review of published literature on survival of $M$. bovis in the environment and surveillance for M. bovis in mammals. Additionally, we examined gray literature (e.g., state, federal reports) to further determine any additional factors that may contribute to WRMAP recommendations.

\section{Results}

2.1. Routes of Transmission of M. bovis. The possible routes of infection of $M$. bovis are related to size, structure, and viability of bacilli in the reservoir and subsequent transmission pathways. Mycobacterium bovis bacilli are 1-4 $\mu \mathrm{m}$ long, small, and nonmotile rods that are characterized by a waxy mycolic acid cell wall that offers protection and the ability to survive outside of the host [15]. Routes of transmission of $M$. bovis are likely dependent upon biology of the host animal as well as environmental variables for areas the host occupies. The high prevalency of pulmonary infections in Eurasian badger and laboratory studies strongly supports inhalation of infectious aerosol particles as the principal infection route [16-18]. Bite wounds were also a source of infection of Eurasian badgers with $M$. bovis and more common in males than females as males are territorial often leading to aggressive defense of territories $[19,20]$. The culture of $M$. bovis from nine of 25 tracheal washings of brushtail possum would suggest a respiratory route of infection perhaps exacerbated by self-grooming and pouched young that led to a constant source of infection (i.e., discharging fistulae on an individual possum; [21]). The most commonly affected tissues of white-tailed deer infected with $5 \times 10^{3}$ cfu (colonyforming units) $M$. bovis would suggest an oral route of transmission through the sharing of feed [22].

Although many routes of transmission of $M$. bovis between and among animal species have been investigated, the minimum infective dose of $M$. bovis has been difficult to quantify. Ingestion of as few as $5 \times 10^{3}$ cfu of M. bovis cattle calves resulted in establishment of infections and lesions
[23], whereas $1 \times 10^{7}$ and $1.3 \times 10^{6} \mathrm{cfu}$ of M. bovis administered orally was needed to establish infections in cattle and sheep, respectively in other studies (Sigurdson 1945, Francis 1947 as cited in [23]). The minimum infective dose for Eurasian badger was found to be $<10 \mathrm{cfu}$ of $M$. bovis through the endobronchial route for latent infection and $10^{3-4} \mathrm{cfu}$ for generalized infection [24, 25]. A dose as small as $20 \mathrm{cfu}$ of $\mathrm{M}$. bovis administered intratracheally to $10^{7} \mathrm{cfu}$ of $M$. bovis injected intramuscularly was found to cause severe tuberculosis in brushtail possum [26, 27]. A minimum infective dose of $M$. bovis necessary to cause TB and the dose actually encountered by wild animals and cattle is difficult to determine definitively, however, most likely routes of transmission of $M$. bovis have been determined for major reservoirs of TB.

\subsection{Modes of Transmission of M. bovis}

2.2.1. Transmission of M. bovis between Captive and Wild Cervids. Ten captive cervid herds have tested positive for M. bovis isolates since captive cervid regulations were implemented in 1999 that included 4, 1, 1, 1, and 3 herds in Michigan, Kansas, New York, Nebraska, and Indiana, respectively $[14,28]$. After several elk were identified as infected with $M$. bovis on a game ranch in Montana, infection was found in adjacent herds of free-ranging mule deer (O. hemionus) with transmission presumed to have occurred by direct contact along the adjoining fence-line [29]. Surveillance from November 1993 to January 1994 found that 2 of 41 free ranging mule deer infected with $M$. bovis likely from direct fence-line contact with positive elk [29]. Evidence of fenceline contact between free-ranging deer and captive deer was documented in Michigan although at a low occurrence [30]. Transmission of TB between wild and captive cervids seems unlikely due to the low occurrence of documented contacts studied at captive facilities.

\subsubsection{Transmission of M. bovis between Captive Cervids and} Cattle. There has been no direct observation of M. bovis transmission between captive cervids and cattle although direct contact between the species has been reported in surveys of farmers but the research findings are less supportive. In a US Department of Agriculture (USDA) survey of farmers, the percentage of dairy operations in the U.S. that reported physical contact between cattle and cervids (either captive or free-ranging) ranged from $20.9 \%$ in the west to $51.6 \%$ in the east, with $90.8 \%$ of survey respondents reporting that cattle "could possibly or sometimes have faceto-face contact with deer" [28]. In that survey, $72.6 \%$ reported contact with free-ranging cervids but only $3.2 \%$ of beef cow-calf operations reported fence-line interactions or commingling with captive cervids [28]. As nationwide occurrence of captive cervids infected with $M$. bovis is very low, transmission of $M$. bovis between captive cervids and freeranging wildlife or cattle may be of little importance. The ability of farmers or ranchers to control contact between cattle and captive cervids (i.e., double fence around captive cervids) would likely prevent transmission of TB. 
2.2.3. Interactions between Wildlife and Cattle. Initially, $M$. bovis transmission from wildlife to cattle (direct) was considered the major route of infection on cattle farms in Michigan [9]. Hill [31] observed only one direct interaction between deer and cattle that involved a female and 2 fawns running by a single cattle and coming within $5 \mathrm{~m}$. Although observations on direct contact was not an objective of the study, elk use of farms around Riding MB National Park in MB, Canada, was positively associated with distance to protected area (i.e., parks) and forested areas that provided suitable cover for elk [32]. A study on cervid damage in Manitoba, Canada identified a reduction in elk damage to stored feed of nearly $50 \%$ after farms fenced stored feed but $18 \%$ of farmers still observed white-tailed deer inside the barrier fencing [33]. The majority of observations or surveys were of farmers that have had their farms test positive for $M$. bovis suggesting that an environment-to-cattle (indirect) transmission of $M$. bovis from wildlife should be the focus of efforts to mitigate transmission of $M$. bovis from deer to cattle and the focus of research on $M$. bovis in the future. Contrary to initial beliefs that direct contact was responsible, indirect contact may be just as important of a route of transmission of $M$. bovis on farms, however, information on shedding of $M$. bovis by wildlife should be considered.

2.2.4. Shedding of M. bovis from Infected Animals. Survival of $M$. bovis in the environment varies from days to months depending on environmental conditions, but there is scant information on routes of shedding or the concentration of M. bovis in excretions from infected wildlife. Hence, the probability of direct and indirect transmission to cattle is difficult to assess. Details on shedding of M. bovis from naturally infected animals of the taxonomic groups commonly found on farms would assist in understanding the probability of transmission (Table 1). In the subsequent section, only reports where "shedding" was defined as the culture M. bovis from saliva, feces, urine, or exudates are reviewed. Shedding that was presumed or otherwise not substantiated was not reported as shedding in subsequent sections.

(1) Shedding by Avian Species. Shedding of M. bovis in avian species has only been investigated in a few species with low to minimal amounts of shedding reported (Table 1). Fecal samples were negative for $M$. bovis in laboratory experiments with American crow (Corvus brachyrhynchos), European starling (Sturnus vulgaris), and mallard ducks (Anas platyrhynchos; $[34,35]$ ). Pigeon (Columba livia) had M. bovis present in excrement for at least 60 days after inoculation [36]. With the wide range of avian species and their presence on farms, additional research on shedding of $M$. bovis appears to be warranted.

(2) Shedding by Marsupialia. Shedding of M. bovis has been reported for brushtail possum in New Zealand and Virginia opossum in North America (Table 1). Diegel et al. [37] inoculated 8 opossum ( 4 orally, 4 intramuscularly) in the laboratory, 5 were positive for $M$. bovis one month after-inoculation, and shedding of $M$. bovis was observed. Oral infection of 4 Virginia opossum resulted in feces positive for M. bovis
1 day and 30 days after-inoculation but these occurred in different individuals [37]. Laboratory aerosol inoculation of 12 Virginia opossum ( 6 high dose, 6 low-dose) resulted in low shedding in one individual in the low dose group on day 60 after -inoculation [38]. Six opossum orally inoculated with high and low doses of $M$. bovis had "uncommon" fecal shedding at both doses suggesting that transmission of $M$. bovis by fecal shedding or direct contact was not likely [38]. Palmer et al. [39] documented excretion of M. bovis in saliva or nasal secretions in raccoon but not in urine or feces leading the authors to claim raccoon were not likely reservoirs of M. bovis. Diegel et al. [37] believe more research is needed on opossum as reservoirs.

(3) Shedding by Insectivora/Rodentia. Only one study has investigated shedding of $M$. bovis by small mammals (Table 1). Clarke et al. [40] inoculated meadow voles (Microtus pennsylvanicus) with $M$. bovis in doses of $5 \times 10^{3} \mathrm{cfu}$ orally (OR group; $n=12$ ) or $1 \times 10^{5} \mathrm{cfu}$ intranasally (IN groups; $n=12$ ) and positive fecal cultures were detected on day 1 in 9 and 8 meadow voles, respectively. Of the surviving meadow voles at day 30, none of 5 in the OR group and 2 of 5 in the IN group had positive fecal cultures. The ability of small mammals to act as reservoirs is not currently supported by field data but does require further research [40]. Clarke et al. [40] inoculated house mice (Mus musculus) and Norway rats (Rattus norvegicus) with $M$. bovis but fecal shedding was not detected.

(4) Shedding by Carnivora. A plethora of research has been conducted on shedding of $M$. bovis in carnivores (Table 1) following the demonstration that European badgers were the primary reservoir in the UK and Ireland. In the laboratory, intravenous inoculation of European badgers with M. bovis resulted in shedding of the bacteria in urine and feces for as long as 1,305 days [41]. Samples from free-ranging European badgers were positive for $M$. bovis in urine, feces, sputum, and bite wounds [42]. The proportion of naturally infected badgers excreting $M$. bovis in urine and feces is low, however, with $11.4 \%$ and $3.8 \%$, respectively, and the concentration of bacilli in the excreta was also very low [25]. Lugton et al. [43] found $M$. bovis present in feces or colonic swabs from 10 of 63-sampled free-ranging feral ferret (Mustela furo). In the laboratory, various doses of $M$. bovis inoculation in raccoon resulted in shedding in saliva and nasal secretions but not in urine or feces [39]. Preliminary results found that prevalence of $M$. bovis was 3\% in raccoon on farms depopulated of cattle following detection of M. bovis from 2006 to 2008 in Michigan [44]. No shedding of M. bovis was found in oral, nasal, or fecal samples from free-ranging coyote in Michigan [45]. Further research on shedding of $M$. bovis in free-ranging carnivore species seems warranted to further understand their role in TB in Michigan.

(5) Shedding by Artiodactyla. Shedding of M. bovis has been studied extensively in a variety of hoofed mammals as a result of recurring infections in cattle and the reservoir host in the US white-tailed deer (Table 1). Low or no shedding of $M$. bovis was documented in free-ranging red deer in New 
TABLE 1: Shedding of Mycobacterium bovis in experimentally and naturally infected free-ranging wildlife species.

\begin{tabular}{|c|c|c|c|}
\hline Species & Study type & Shed & Author \\
\hline $\begin{array}{l}\text { Crow Corvus brachyrhynchos, } \\
\text { starling Sturnus vulgaris }\end{array}$ & Laboratory inoculation & $\begin{array}{l}\text { Negative fecal samples, concluded no shedding } \\
\text { occurs }\end{array}$ & Butler et al. [34] \\
\hline Pigeon Columba livia & Laboratory inoculation & $\begin{array}{l}\text { Positive fecal samples for at least } 60 \text { days after } \\
\text { inoculation }\end{array}$ & Fitzgerald et al. [36] \\
\hline $\begin{array}{l}\text { Mallard ducks } \\
\text { Anas platyrhynchos }\end{array}$ & Laboratory inoculation & $\begin{array}{l}\text { Negative fecal samples, concluded no shedding } \\
\text { occurs }\end{array}$ & Fitzgerald et al. [35] \\
\hline $\begin{array}{l}\text { Brushtail possum } \\
\text { Trichosurus vulpecula }\end{array}$ & $\begin{array}{l}\text { Laboratory inoculation of } \\
\text { wild caught individuals }\end{array}$ & $\begin{array}{l}\text { Transmission between infected brushtail } \\
\text { possum and controls was noted with gross } \\
\text { lesion distribution consistent with aerosol } \\
\text { transmission }\end{array}$ & Corner et al. [16] \\
\hline $\begin{array}{l}\text { Virginia opossum } \\
\text { Didelphis virginianus }\end{array}$ & Laboratory oral inoculation & $\begin{array}{l}1 \text { Virginia opossum fecal culture tested positive } \\
\text { after } 1 \text { day after inoculation and another on } \\
\text { day } 31 \text { after inoculation }\end{array}$ & Diegel et al. [37] \\
\hline $\begin{array}{l}\text { Virginia opossum } \\
\text { Didelphis virginianus }\end{array}$ & $\begin{array}{l}\text { Laboratory aerosol } \\
\text { inoculation of wild caught } \\
\text { individuals }\end{array}$ & $\begin{array}{l}\text { Only } 1 \text { of } 12 \text { Virginia opossum had a positive } \\
\text { fecal sample during the } 90 \text { study }\end{array}$ & Fitzgerald et al. [38] \\
\hline $\begin{array}{l}\text { Vole Microtus pennsylvanicus, } \\
\text { mice Mus musculus, } \\
\text { rat Rattus norvegicus }\end{array}$ & Laboratory inoculation & $\begin{array}{l}\text { Positive samples of fecal cultures from the } \\
\text { Meadow vole only }\end{array}$ & Clarke et al. [40] \\
\hline $\begin{array}{l}\text { European badger } \\
\text { Meles meles }\end{array}$ & $\begin{array}{l}\text { Samples from free-ranging } \\
\text { groups }\end{array}$ & $\begin{array}{l}\text { Positive samples from urine, feces, and bite } \\
\text { wounds }\end{array}$ & Chambers et al. [42] \\
\hline $\begin{array}{l}\text { European badger } \\
\text { Meles meles }\end{array}$ & $\begin{array}{l}\text { Samples from free-ranging } \\
\text { animals }\end{array}$ & $\begin{array}{l}\text { Positive samples from sputum, urine, feces, } \\
\text { and bite wounds }\end{array}$ & Clifton-Hadley et al. [2] \\
\hline $\begin{array}{l}\text { European badger } \\
\text { Meles meles }\end{array}$ & $\begin{array}{l}\text { Necropsies of animals } \\
\text { found dead }\end{array}$ & $\begin{array}{l}\text { Concluded that } M \text {. bovis could be shed via } \\
\text { sputum, urine, and feces }\end{array}$ & $\begin{array}{c}\text { Clifton-Hadley (cited in } \\
\text { Gallagher et al. [90] }\end{array}$ \\
\hline $\begin{array}{l}\text { European badger } \\
\text { Meles meles }\end{array}$ & Laboratory inoculation & $\begin{array}{l}\text { Positive samples from urine and found in feces } \\
\text { for } 165-1305 \text { days }\end{array}$ & Little et al. [41] \\
\hline Feral ferret Mustela furo & $\begin{array}{l}\text { Examination of captured } \\
\text { free-ranging individuals }\end{array}$ & $\begin{array}{l}\text { Oral cavity was the most common site of } \\
\text { excretion of } M . \text { bovis; further positive samples } \\
\text { of shedding came from tracheobronchial, } \\
\text { urine, feces, and mammary gland samples }\end{array}$ & Lugton et al. [43] \\
\hline Raccoon Procyon lotor & $\begin{array}{l}\text { Inoculated individuals with } \\
\text { single oral doses of } M . \text { bovis } \\
\text { (ranging from } 30 \text { to } \\
1.7 \times 10^{5} \mathrm{cfu} \text {, five daily oral } \\
\text { doses (ranging from } 10 \text { to } \\
1 \times 10^{5} \mathrm{cfu} \text { ), or a single } \\
\text { intravenous dose of } \\
1 \times 10^{5} \mathrm{cfu}\end{array}$ & $\begin{array}{l}\text { Low doses of } M . \text { bovis in saliva or nasal } \\
\text { secretions but no shedding in urine or feces }\end{array}$ & Palmer et al. [39] \\
\hline Coyote Canis latrans & $\begin{array}{l}\text { Samples from free-ranging } \\
\text { individuals that tested } \\
\text { tissue positive for M. bovis }\end{array}$ & $\begin{array}{l}\text { Authors concluded that shedding was minimal } \\
\text { based on negative culture samples from oral, } \\
\text { nasal, and feces samples }\end{array}$ & Berentsen et al. [45] \\
\hline Red deer Cervus elaphus & $\begin{array}{l}\text { Samples from free-ranging } \\
\text { individuals }\end{array}$ & $\begin{array}{l}\text { Low shedding in feces and in nasal, pharyngeal, } \\
\text { and tracheal swabs but no shedding in urine }\end{array}$ & Lugton et al. [46] \\
\hline $\begin{array}{l}\text { Marsh deer } \\
\text { Blastocerus dichotomus }\end{array}$ & $\begin{array}{l}\text { Esophageal-pharyngeal } \\
\text { fluids from } 53 \text { free-ranging } \\
\text { individuals }\end{array}$ & Concluded no shedding through this route & Luna et al. 2003 [47] \\
\hline $\begin{array}{l}\text { Domestic cattle } \\
\text { Bos taurus }\end{array}$ & $\begin{array}{l}\text { Inoculation (low dose, } \\
10^{4} \mathrm{cfu} \text {; high dose } 10^{6} \mathrm{cfu} \\
\text { intranasal and intratracheal } \\
\text { inoculation) of calves in a } \\
\text { laboratory setting }\end{array}$ & $\begin{array}{l}\text { Nasal shedding was detected in } 21 \text { of } 24 \\
\text { animals, but no calves given a low-dose shed }\end{array}$ & McCorry et al. [50] \\
\hline
\end{tabular}


TABle 1: Continued.

\begin{tabular}{|c|c|c|c|}
\hline Species & Study type & Shed & Author \\
\hline $\begin{array}{l}\text { White-tailed deer } \\
\text { Odocoileus virginianus }\end{array}$ & $\begin{array}{l}\text { Laboratory inoculation of } \\
\text { mature female white-tailed } \\
\text { deer with intratonsilar } \\
\text { instillation of } 2 \times 10^{3} \text { (low } \\
\text { dose) or } 2 \times 10^{5} \text { (high } \\
\text { dose) cfu of M. bovis. }\end{array}$ & $\begin{array}{l}\text { Authors conclude that the results indicated that } \\
\text { M. bovis persists in tonsilar crypts for } \\
\text { prolonged periods and can be shed in saliva } \\
\text { and nasal secretions }\end{array}$ & Palmer et al. [48] \\
\hline $\begin{array}{l}\text { White-tailed deer } \\
\text { Odocoileus virginianus }\end{array}$ & $\begin{array}{l}\text { Laboratory inoculation and } \\
\text { co-mingling }\end{array}$ & $\begin{array}{l}\text { Positive at } 63 \text { (nasal swab), } 90 \text { (oral), and } 113 \\
\text { (rectal) days post inoculation; positive at } 69 \\
\text { (oral and nasal) days post co-mingling with } \\
\text { inoculated; positive sample in feed on day } 63 \\
\text { and } 150 \text { post inoculation, positive sample on } \\
\text { hay on day } 90 \text { and } 210 \text { days post inoculation }\end{array}$ & Palmer et al. [49] \\
\hline
\end{tabular}

Zealand and marsh deer (Blastocerus dichotomus) in Brazil, respectively $[46,47]$. Laboratory inoculations of domestic cattle and white-tailed deer demonstrated that $M$. bovis can be shed in saliva, nasal secretions, urine, and feces [48-50]. White-tailed deer in the low-dose group $\left(2 \times 10^{3} \mathrm{cfu} ; n=4\right)$ and high dose group $\left(2 \times 10^{5} \mathrm{cfu} ; n=4\right)$ had tonsillar swabs positive for M. bovis in one (at day 14) and 2 (at day 35) deer, respectively. Oral swabs for white-tailed deer yielded $M$. bovis at 63 and 80 days for one deer in the low dose group from no deer in the high-dose group [48]. Of 4 white-tailed deer that received $2 \times 10^{8} \mathrm{cfu}$ of $M$. bovis in by intratonsillar instillation, detection of $M$. bovis in tonsillar, oral, nasal, and rectal swabs was possible in at least one deer at 63, 90, and 113 days after-inoculation [49]. Calves infected intranasally or intratracheally with the low dose $\left(1.1 \times 10^{4} \mathrm{cfu}-2.0 \times 10^{4} \mathrm{cfu}\right.$; $n=6$ per route $)$ and high dose $\left(1.7 \times 10^{6} \mathrm{cfu}-4.0 \times 10^{5} \mathrm{cfu}\right.$; 6 per route) of $M$. bovis resulted in more severe pathology and more episodes of shedding in the high dose calves 80 days post-inoculation [50]. Free-ranging cervids have long been implicated in transmission of $M$. bovis and shedding has substantiated their ability to maintain TB and infect cattle when overlap of range has been documented.

\subsection{Survival of $M$. bovis under Experimental Conditions.}

Since the 1930s, a variety of investigations have been published on what may influence survival of $M$. bovis (referred to Bacilli tuberculosis in earlier papers), including examination of artificial and natural inoculations and variation in temperature, moisture, and substrates. Numerous factors contribute to the survival or loss of viability of $M$. bovis in the environment, and these have been investigated under both laboratory and natural environmental conditions.

Williams and Hoy [51] examined persistence of M. bovis in Great Britain in artificially and naturally infected soil, cattle feces, and intestinal content. Guinea pigs were used to determine presence of $M$. bovis via inoculation with treatment material. Under natural shaded conditions on pastures, positive samples from cattle feces inoculated with $M$. bovis were detected up to 5 months post-application during winter but only up to 2 months during spring and summer. If the feces were shaded from sunlight, however, then positive samples were observed post-application for up to 4 months during summer and 6 months in autumn. All intestinal samples from tuberculous cattle spread on pasture were positive for $M$. bovis immediately after application but subsequently tested negative for up to 4 months. If stored in a cool cellar, artificially and naturally infected feces tested positive for 24 months and 12 months, respectively. Artificially infected liquid feces stored underground tested positive for at least 4 months.

2.3.1. Survival of M. bovis in Soil-Related Substrates. Maddock [52] investigated the survival time of M. bovis in soil, cattle feces, and feces and soil mixtures exposed in open pastures of Great Britain. The viability of $M$. bovis on growing pasture grass was also explored. Porous pots were placed at ground level within an open pasture and filled with soil, feces, or a mixture of feces and soil; and $M$. bovis emulsion was subsequently added. Guinea pigs were used to determine presence of $M$. bovis via inoculation with treatment material. Soil, feces, and soil and feces-mixture treatments all tested positive for up to 6 months post-application. Sampling from the pots occurred from June to December. An emulsion of $M$. bovis material (tuberculous material collected from abattoirs) was sprayed on grass growing in a pasture at 3 different dilution levels (Plot I: 120,000 M. bovis/ $\mathrm{ft}^{2}$; Plot II: 1.2 million; Plot III: 120 million). Plot III tested positive up to 49 days after application but plot I only tested positive for up to 14 days after application. The author noted (no measurements reported) there was heavy rain after application followed by heat and dryness during the grass experiment which was conducted from April to June.

Maddock [53] conducted field investigations from 1932 (grass and soil experiment) to 1933 (grass experiment only) as a continuation of the experiment published in Maddock [52] with the purpose of examining survival of $M$. bovis given annual variation in weather from the previous studies in 1932 and 1933. The average mean temperature for the months of July, August, and September, 1932 was $2.9^{\circ} \mathrm{C}$ higher than that of the same period in 1931. The maximum temperature in 1932 was $34.8^{\circ} \mathrm{C}$, as compared with $24.4^{\circ} \mathrm{C}$ for 1931. Postapplication treatments tested positive for $M$. bovis up to 2, 5, and 5 months for soil, feces, and soil/feces mixture, respectively. The grass experiment was conducted from April to September in 1932 and from June to September 1933. During 1932, positives were detected at 14, 28, and 
49 days after application for plots I, II, and III, respectively. The temperature (no measurements reported) during the summer of 1933 was noted as very hot and attempts were made to detect $M$. bovis on grass with application of dilutions of 5 million B. tuberculosis $/ \mathrm{ft}^{2}, 7$ million, and 25 million. Only the plot inoculated with 7 million B. tuberculosis $/ \mathrm{ft}^{2}$ had a positive detection, occurring at 63 days after application but not at 83 or 105 days after application.

Van Donsel and Larkin [54] investigated the survival of $M$. bovis in soil and on radishes and lettuce in raised garden plots (lined plywood boxes). Plots were outside under natural conditions during summer in Cincinnati, $\mathrm{OH}$, USA. Soil and vegetables were sprayed or irrigated with either sewage effluent or sludge 2 weeks after planting with $M$. bovis cultures at $10^{6} \mathrm{cfu} / \mathrm{mL}$. Culture media was used to determine presence of $M$. bovis. Effluent plots tested positive for $M$. bovis for up to 29, 13, and 35 days after application for soil, radishes, and lettuce, respectively. Sludge plots tested positive for $M$. bovis for 29, 10, and 35 days after application for soil, radishes, and lettuce, respectively. Contamination (e.g., mold) became too great in soil after 29 days to accurately identify $M$. bovis in samples.

Duffield and Young [55] investigated survival of $M$. bovis in artificially inoculated dry and moist soils and bovine feces under various environmental conditions for 32 weeks in tropical northern Australia. Environmental conditions included laboratory (mean daytime temperature $=$ $23^{\circ} \mathrm{C}$ ) and sun (mean daytime temperature $=43^{\circ} \mathrm{C}$ ), shade $\left(80 \%\right.$ shade cloth, mean daytime temperature $\left.=34^{\circ} \mathrm{C}\right)$, and dark (containers covered with aluminum foil, mean daytime temperature $=32^{\circ} \mathrm{C}$ ) in the external environment. Identification of $M$. bovis was performed using culture media, drug sensitivity, and guinea-pig (Cavia porcellus) inoculation [55]. All tested environmental conditions were conducted using sterile and non-sterile substrates. Substrates were dry, sandy loam pH 6.3-6.7; sandy loam with 30\% (v/w) moisture content; fresh feces from cattle. Substrates inoculated with $5 \times 10^{8} \mathrm{cfu}$ of an $M$. bovis field strain were used to inoculate $50 \mathrm{~g}$ of substrate. Samples positive for M. bovis were identified up to 4 weeks after inoculation for nonsterile substrates in dry and moist soils in shade, dark, and laboratory conditions. Samples positive for M. bovis were also observed up to 4 weeks after inoculation in sterile-moist soil in shade and dark conditions. Samples positive for $M$. bovis were not observed in the remaining combinations of tested substrate and environmental conditions. The authors concluded that the low survival of M. bovis, as compared to other studies $[51,52]$, was due in part to higher temperatures during the study.

Jackson et al. [21] investigated the survival of M. bovis in New Zealand using inoculated cotton ribbons placed in brushtail possum dens, open pasture, and the forest floor. The inoculum was $50 \mu \mathrm{L}$ of $M$. bovis at a concentration of $1-5$ $\times 10^{8}$ organisms per milliliter. Samples positive for M. bovis were determined using culture media. Samples positive for M. bovis were observed for up to 4 days on open pasture during spring and summer, and on the forest floor during summer. Samples positive for $M$. bovis were observed for up to 7 days underground in dens during summer and 14-28 days on forest floor during winter. Authors concluded that bacteria survival increases as temperature decreases and has higher survival during spring and winter than summer.

Young et al. [56] investigated the survival of $M$. bovis Bacillus Calmette-Guérin (BCG) in soil collected from farms that tested positive for M. bovis in Ireland. Soil samples were monitored in a laboratory after inoculation with $10^{8}$ cells of $M$. bovis BCG. Soil samples were stored at $15,20,25$, and $37^{\circ} \mathrm{C}$ with various water moisture levels of $-1,600,-400$, $-66,-33,-20$, and $-10 \mathrm{kPa}$ matric potential. Samples positive for live organisms of $M$. bovis were detected using culture media and Polymerase Chain Reaction (PCR). Experiments revealed that $M$. bovis $\mathrm{BCG}$ survival was optimal at $37^{\circ} \mathrm{C}$ with moist soil $(-20 \mathrm{kPa} ; 30 \%$ [vol/wt] $)$. The authors concluded that $M$. bovis can persist in the farm environment for up to 10 days outside of its hosts and survival was influenced by climatic factors.

2.3.2. Survival of M. bovis in Feces. Recovery of M. bovis from cattle feces that were artificially infected with (emulsified tuberculous bovine lung lesions) and spread on pasture was recovered on pasture 2-4 months later with survival longer during winter (5 months) than during summer $(<2$ months), although larger doses of $M$. bovis inoculums were used for winter than summer experiments [51]. M. bovis was recovered for naturally infected feces stored in cool dark conditions after 12 months and for 2 years in experimentally infected feces stored in a similar manner [51].

Tanner and Michel [57] examined the survival of M. bovis in South Africa using naturally infected lung or lymph node tissue and artificially inoculated cattle feces with $8 \times 10^{7}$ organisms. Fecal samples were placed on polystyrene trays and placed in shaded or nonshaded cages (protected from ants and animals) in dry and moist soil areas and trees across 4 seasons (winter, spring, summer, and autumn). A set of fecal samples were also placed $20 \mathrm{~cm}$ underground in moist soil plots. Positive samples of $M$. bovis were identified via culture media and PCR. No positives were observed beyond 5 days for buried samples. For naturally infected samples in nonshaded conditions during winter, M. bovis was detected for as long as 27 days in moist soil areas but as long as 42 days in the shade. During summer, M. bovis was detected for as long as 14 days in shaded moist soil areas but only up to 5 days in trees and dry soil plots. During spring, M. bovis was detected for as long as 14 days in moist soil areas but only up to 5 days in shade and dry soil conditions. During autumn, M. bovis was detected for as long as 7 days in moist soil plots but only 2-5 days in other conditions.

Tanner and Michel [57] also investigated artificially infected samples from cattle feces in non-shaded conditions. During winter, M. bovis was detected for as long as 27 days in moist and dry soil plots but only for up to 5 days in shade under trees. During spring, M. bovis was detected for as long as 21 days in moist soil areas but only up to 2 days in trees. During summer, M. bovis was detected for 5 days in shade under trees, dry soil, and moist soil plots. During autumn, M. bovis was detected for as long as 14 days in moist plots but only 5-7 days in other conditions. For artificially infected fecal samples in shaded conditions during winter, M. bovis 
was detected for as long as 14 days in moist and shade tree plots but only up to 5 days in dry soil conditions [57]. During summer, M. bovis was detected for only up to 5 days in shade, dry soil, and moist soil plots. During spring, M. bovis was detected for as long as 21 days in moist and shade tree plots but only up to 14 days in dry soil. During autumn, M. bovis was detected for as long as 14 days in dry and moist plots but only up to 7 days in shade tree plots. The authors concluded that moisture and temperature greatly affected the duration of survival of $M$. bovis in the environment.

2.3.3. Survival of M. bovis in Feed. Palmer and Whipple [58] examined the survival of $M$. bovis on feedstuffs often used for feeding white-tailed deer in Michigan such as apples, corn, potatoes, and sugar beets. Each sample was inoculated with $1 \mathrm{~mL}$ volume of a bacterial suspension containing $1.1 \times 10^{6} \mathrm{cfu}$ of $M$. bovis then randomly placed in storage with 1 of 3 environmental temperatures $\left(-20^{\circ} \mathrm{C}\right.$, freezing; $8^{\circ} \mathrm{C}$, refrigeration; $23^{\circ} \mathrm{C}$, room temperature). Samples positive for $M$. bovis were identified using culture media and genetic isolation. Survival of M. bovis was for at least 7 days on all feedstuffs at all temperatures tested. At the termination of the study (112 days), M. bovis could be recovered from all feedstuffs at $-20^{\circ} \mathrm{C}$, from apples, corn, hay, and potatoes at $8^{\circ} \mathrm{C}$, and from apples, corn, and potatoes at $23^{\circ} \mathrm{C}$. Carrots and sugar beets were the least favorable substrate for survival, however, $M$. bovis could be recovered from both at 112 days at $-20^{\circ} \mathrm{C}$ and 14 and 84 days, respectively, at $8^{\circ} \mathrm{C}$.

Fine et al. [59] investigated the survival of $5 \times 10^{4} \mathrm{cfu}$ M. bovis artificially applied to corn, hay, soil, and water exposed to natural conditions within an outside exclosure in Michigan. Substrates were inoculated with 50,000 cfu of M. bovis extracted from bovine lymph node that tested positive for M. bovis. Samples positive for M. bovis were identified via culture media and genetic isolation. During the autumn/winter sampling period, samples positive for $M$. bovis were identified up to 37,43 , and 28 days after inoculation in corn, hay, and soil substrates, respectively. During the winter/spring, samples positive for $M$. bovis were observed up to 26, 26, and 88 days after inoculation for corn, hay, and soil substrates, respectively. During the spring/summer, samples positive for $M$. bovis were observed up to 3,0 , and 11 days post inoculation in corn, hay, and soil substrates, respectively. There was no significant substrate affect, but $M$. bovis had a greater persistence in water in summer. Shade increased persistence of $M$. bovis, except during winter/spring. The authors concluded that survival of $M$. bovis decreased as temperatures increased, solar radiation intensified, and evapotranspiration increased.

2.3.4. Survival of M. bovis in Water. Survival of M. bovis in water has been documented at up to 400 days in running water even though dilutions in running water will decrease the overall numbers of the bacteria in samples collected [60]. Fine et al. [59] documented survival of M. bovis in artificially contaminated water that was exposed to natural environmental conditions and showed that the bacilli could survive for 58,21 , and 48 days during autumn/winter, winter/spring, and spring/summer, respectively. The isolation of $M$. bovis from water troughs or natural water sources exposed to naturally infected animals has not been reported. Michel et al. [61] housed experimentally infected African buffalo (Syncerus caffer) with naïve buffalo that shared water troughs but were unable to find $M$. bovis in water samples even though buffalo tested positive several months posttrial. Transmission of $M$. bovis in water either by infected cattle or wildlife is unlikely based on infective dose needed and conditions necessary for survival of an infective dose in water.

\subsubsection{Survival of $M$. bovis in relation to Farm Practices.} Studies examining the survival of $M$. bovis in the natural environment rarely have attempted to determine the halflife of $M$. bovis survival, however, they are very informative and hold the key to some of the variables that determine viability in the environment. High temperatures lead to decreased survival of $M$. bovis $[21,57,59]$, and vice versa, lower temperature lead to higher probability of survival $[21,62]$. Moisture content seems correlated with survival such that lower available moisture leads to cell death [56, $57,59]$. Under the conditions investigated, environmental survival of $M$. bovis ranges from only a few days to many months with survival influenced by exposure to sunlight, temperature, soil type, moisture content, $\mathrm{pH}$, and whether the bacilli were in soil, water, feed stuffs, or air. The intricate combination of factors involved in survival of $M$. bovis on farms makes knowledge of these intricate relationships integral to understanding transmission of TB in regions that have wildlife and domestic animal host.

Recurring cases in Ireland were related to no mineral lick supplements being supplied to cattle (i.e., nutritional effects), purchase of a bull (i.e., cattle movements among farms), presence of cubicle housing, rough grazing areas (i.e., poor quality soil), and presence of European badgers on the farm [63]. Buying in cows (i.e., purchasing cattle from an outside source as opposed to operating a closed herd), purchase of $>50$ cattle during the study period, and storing manure for at least 6 months increased chance of transient (i.e., initial $M$. bovis exposure) breakdown on farms; high stocking density ( $\geq 3$ cattle/ha) decreased odds of $M$. bovis although stocking density was a categorical variable (i.e., low, intermediate, high) based on the 5-year average stocking density relative to the area of grassland on the farm [64]. Buying in cows and the use of concrete storage bins covered by plastic sheets (hereafter referred to as silage clamps) on the farm increased the risk of repeated $M$. bovis infection; farming of a mixed herd (i.e., both dairy and beef cattle) and providing hay to cattle decreased chance of repeated M. bovis infection [64].

(1) Livestock Grazing. Grazing cattle tend to ingest soil when grazing on vegetation that is short suggesting that overstocking or overgrazing of areas can increase transmission of $M$. bovis $[3,65]$. Within-herd transmission has been suggested to be greater with cattle housed indoors rather than in pastures [65]. Poorly ventilated cattle housing, high density of cattle, high humidity, and low sunlight is an ideal environment for survival of $M$. bovis and lead to increased potential for 
transmission $[65,66]$. Farm yard (composted) manure must be exposed to a mean temperature of $60-70^{\circ} \mathrm{C}$ for 3 weeks during composting to destroy $M$. bovis bacilli, but most solid dung heaps were not able to reach that high temperature (Hahesy 1996 in [65]). Survival in slurry can vary from 10 weeks to 6 months with storage temperature being the key factor determining survival (Hahesy et al. 1992 in [65]). Survival in slurry can last 17 months at $40-45^{\circ} \mathrm{C}$ (Turgenbaev 1986 in [65]) but only 30 days at $54^{\circ} \mathrm{C}$ (Vera et al. 1988 in [65]).

(2) Feeding of Livestock. Several Mycobacterium spp. have been documented to lay dormant for prolonged periods under anaerobic conditions prior to reactivation of endogenous infection [67-69]. In such conditions, M. bovis develops a thick cell wall and enters a nonreplicating or dormant state $[65,67]$. The process of silage production (i.e., zero oxygen concentration within days of ensiling) may induce $M$. bovis to enter a dormant state $[65,67]$. As the temperature during ensiling and grass storage can reach $30^{\circ} \mathrm{C}[70]$, and the optimal temperature for M. bovis survival is $37^{\circ} \mathrm{C}[71]$, silage or grass clamp preparation and storage provide ideal conditions for $M$. bovis survival and should be investigated as a possible source for $M$. bovis infections on farms in Michigan.

(3) Stored Feed. Feed storage and fencing to exclude wildlife have been considered the primary method to decrease the transmission of M. bovis on farms [59, 72]. From 2000 to 2004, 8 of 12 farms surveyed stored round hay bales outside and were unprotected from wildlife [73]. Stored feed and supplemental feed has been implicated in contributing to transmission of $M$. bovis in white-tailed deer in Michigan [8]. Results from modeling efforts indicated that prior to the 1998 baiting ban in Michigan, prevalence of $M$. bovis on farms had a positive relationship with the percentage of sites that provided fruits and vegetables (i.e., apples, carrots, sugar beets) but a negative relationship with percentage of sites that provided grain [8]. Indirect transmission by contaminated feed was documented in a laboratory setting by feeding leftover grain consumed by deer infected with $M$. bovis to naïve deer for 120 days resulting in infection of all naïve deer $(n=$ 4; [22]). Palmer and Whipple [58] documented that M. bovis was present on various supplemental feeds at 3 temperatures $\left(-20^{\circ} \mathrm{C}, 8^{\circ} \mathrm{C}, 23^{\circ} \mathrm{C}\right)$ for at least 7 days and at $23^{\circ} \mathrm{C} \mathrm{M}$. bovis was isolated for as long as 112 days. Silage appeared to be more accessible to European badgers in Ireland and 100\% of the farms that experienced persistent breakdowns of $M$. bovis fed grass silage [64].

(4) Wildlife Activity on Farms. The influence of wildlife activity on transmission of $M$. bovis depends on possible reservoirs or spillover hosts and their ability to transmit disease. Elk have been reported to use the same pastures, streams, ponds, cattle troughs, and mineral supplements as cattle near Riding Mountain National Park, Manitoba, Canada and were assumed to be responsible for the continued presence of $M$. bovis in the region [32]. Visits to farm yards and areas used by cattle were studied in Michigan where sixteen radiocollared white-tailed deer in the TB core area were monitored. Incursions into farm yards were infrequent and undertaken by few of the deer but 2 deer ( $12.5 \%$ of study subjects) were responsible for $80 \%$ of the visits to farm yards [74]. Several medium-sized mammals (i.e., European badgers, brushtail possum, raccoon) have been observed using farms, feeding troughs, and pastures. European badger feces were observed in feed troughs on cattle farms in the UK and shedding in feces has been frequently reported [11, 42]. Brushtail possum avoided direct contact with cattle but used pastures occupied by cattle and the access of cattle to areas where possum denned was directly associated with transmission of $M$. bovis from brushtail possum to cattle [75]. Hill [31] documented 273, 248, and 112 indirect interactions with cattle by white-tailed deer, other mammals (raccoon, rabbit, coyote, and Virginia opossum), and eastern wild turkey (Meleagris gallopavo), respectively, over 2 years in Michigan. Indirect interactions between cattle and white-tailed were dominated by deer using pastures and silage storage areas; deer fed from hay racks or silage troughs on only one occasion [31]. Most interactions by mammals other than deer were observations passing through pastures without visiting cattle feeding areas.

(5) General Farm Practices. Mixed dairy and beef enterprises were at greater risk than nonmixed operations for contracting $M$. bovis in Italy likely due to the cattle movement among farms which was considered a major risk factor [76]. In the UK, Reilly and Courtenay [64] found increased odds of both transient breakdown (i.e., cattle on a farm only positive once for M. bovis) and persistent breakdown (i.e., cattle on a farm repeatedly positive for $M$. bovis) on farms that imported cows but only transient breakdowns for farms that purchased $>50$ head of cattle. Several studies have indicated that movement of cattle between farms was a contributing factor to M. bovis transmission in Europe $[63,77]$. In England, increased risk of TB was associated with movement of cattle onto farms from markets or farm sales suggesting an outside source of TB infection [77]. Importing $>50 \%$ of cattle annually, however, did not increase odds of a farm coming down with $M$. bovis in Michigan [13]. In North America, a survey in 17 of the Nation's major dairy states found 4 out of 10 dairy operations surveyed between 1996 and 2006 brought cattle onto the operation to replace culled cows or to increase herd size [28]. For large dairy operations of $\geq 500$ head, percent of new additions ranged from $1 \%$ for preweaned calves to $61.6 \%$ for any beef or dairy cattle. For small dairy operations of $<100$ head, percent of new additions ranged from $1 \%$ for beef heifers and cows to $35.6 \%$ for any beef or dairy cattle. Fine [73] surveyed 13 Michigan farmers (4 dairy, 7 beef, 2 small beef feeder) with mean herd size of 74 cattle (range: 14-239) that had cattle test positive for M. bovis between 2000 and 2004. "About half" of the farms surveyed purchased $100 \%$ of their cattle from outside sources suggesting that cattle importation increases likelihood of cattle testing positive for M. bovis that is similar to finding in other countries.

2.4. Destruction of $M$. bovis. Although the previous sections detailed survival and hence, death of $M$. bovis under 
various conditions (i.e., temperature, humidity, and ultraviolet light), killing or active destruction of bacilli responsible for TB would be beneficial in farm buildings or structures that previously housed cattle positive for M. bovis. Although decontamination of surfaces is common for human practices [78], we found only one study that directly investigated the destruction of $M$. bovis with volatile chemicals [79]. Scanlon and Quinn [79] evaluated the ability of 5 volatile chemicals to inactivate the bacteria in cattle slurry. Acetone at concentrations of $22.5 \%$ inactivated $M$. bovis in under 24 hours and a $1.0 \%$ concentration of ammonium hydroxide inactivated M. bovis after 36 hours. Chloroform, ethyl alcohol, and xylene at concentrations of $0.5 \%, 17.5 \%$, and $3 \%$, respectively, inactivated $M$. bovis within 48 hours [79]. Due to the cost, safety considerations, and risk of environmental pollution from volatile chemicals, use of chemicals to inactivate $M$. bovis should be critically evaluated and is likely not a practical means of treating farms previously found to be positive for M. bovis [79].

\section{Discussion}

3.1. Wildlife Risk Mitigation Project Strategy. The WRMAP was a collaborative effort between the Michigan Department of Agriculture and Rural Development, Michigan State University Extension, USDA (Veterinary Services, Wildlife Services), and the Natural Resources Conservation Service to help Michigan livestock producers protect their cattle from M. bovis. The WRMAP was intended to educate farmers on potential risky farm practices that may lead to $M$. bovis contamination and to identify measures to reduce their risk. After a farmer commits to a WRMAP, he/she implements the WRMAP followed by verification of the plan by technical experts. The WRMAP contains specific components that could reduce $M$. bovis transmission on farms that includes (1) livestock feeding practices, (2) feed storage, (3) livestock water sources, (4) wildlife activity, and (5) general farm practices.

Livestock grazing and feeding practices greatly influence transmission of disease because various factors that farmers use to efficiently feed cattle can contribute to survival of $M$. bovis. Grazing cattle can ingest soil when grazing on vegetation that is short as a result of overstocking or overgrazing of areas that can be addressed by farmers [3, 65]. Farmers often use manure or slurry as fertilizer for crops and these areas are then often used for cattle grazing. Manure and slurry must be exposed to the proper temperatures for long enough duration to destroy $M$. bovis bacilli prior to spreading on pasture or crop fields that are intended for grazing by cattle (Hahesy 1996 in [65]). Although crop fields and pastures are typically on open lands and in direct sunlight limiting survival of $M$. bovis, spreading improperly processed manure or slurry should be avoided.

The type of feed a farm supplies to cattle influences the amount of deer damage because deer preference for feed dictates their level of motivation to attain such feed [72]. Damage to feed could influence infection from deer and was considered an important mitigation measure in Minnesota programs. For example, herds surveyed in the Minnesota core
TB zone had the most deer damage to silage (71\%) followed by alfalfa (2nd/3rd cutting; 34\%) and beet pulp (38\%) with grass hay receiving the least amount of damage (2\%; [72]). Feeding or storing of fruits and vegetables was associated with higher prevalence in deer because one deer may not consume an entire fruit or vegetable and if sufficiently contaminated has the potential to infect the next deer or cattle that consumed the partially consumed fruit or vegetable [8]. Furthermore, feeding grains was negatively associated with TB prevalence in deer [8] because it was easier to disperse thus decreasing the density of deer feeding in the same areas when compared to feeding hay. Farmers feeding bales of hay year-round would appear to be more at risk of contracting $M$. bovis because hay could be left uneaten, and if contaminated with $M$. bovis, they provide a source of disease transmission to other animals (i.e., cattle, deer).

Feed storage and fencing to exclude wildlife have been considered the primary method to decrease the transmission of $M$. bovis on farms in Michigan and Minnesota [14, 59, 72]. Increased efforts by the USDA and MDARD have provided hoop barns or deer-proof fencing to protect stored feed. Previous research has indicated that protection of feed should be a primary focus of the WRMAP because indirect transmission of M. bovis can occur from up to 112 days under the proper environmental conditions. Although less likely, an additional practice not included in WRMAP includes potential for importing stored silage or hay and the likelihood of introducing $M$. bovis from outside sources of feed. Previous studies documented that stored manure and feed increased the risk of $M$. bovis infection [64] but were unable to document if feed purchased from outside sources could be a route of transmission.

Although $M$. bovis has been shown to survive in water for extended periods, the role of transmission of $M$. bovis via water sources remains unknown [80]. Current risk mitigation measures require farmers to exclude cattle from ponds or water bodies that may be accessible to wildlife and exclude wildlife from cattle water troughs or water storage tanks [14, 81]. Although M. bovis has been shown to survive in water for extended periods (i.e., days to months) under artificial conditions and is currently within the WRMAP, the role of transmission of $M$. bovis via water sources remains unknown and likely highly dependent upon the proper combination of climatic conditions, water properties (i.e., standing or running water), level of contamination, infective dose, and dilution.

Wildlife activity has been linked to infections from wildlife to cattle for recurring cases of $M$. bovis on cattle farms in Michigan, USA, and the UK but the exact route is difficult to determine $[14,82,83]$. The influence of wildlife activity on transmission of $M$. bovis has been the focus of mitigation measures to limit access to farms for badger in the UK and Ireland $[11,63]$, brushtail possum in New Zealand [75], white-tailed deer in Michigan and Minnesota, USA $[14,81]$, and elk in Canada [32]. It is now believed, however, that indirect transmission of $M$. bovis, through sharing of contaminated feed or substrates, was the more likely route of transmission compared to direct contact of cattle with infected wildlife. Several studies on interactions by mammals 
with cattle found wildlife passing through cattle use areas or interacting directly with feed, stored feed, or water troughs with little to no direct contact between cattle and wildlife. Continued exclusion of wildlife from cattle through various changes in farms practices should be the focus of WMRAP and the exclusionary measures performed on a farm are dependent upon the host species in a respective country or region experiencing $\mathrm{TB}$ in cattle.

General farm practices have also been responsible for recurring cases of $M$. bovis infection in cattle on farms in Ireland such as no mineral lick supplements being supplied to cattle (i.e., nutritional effects), purchase of a bull (i.e., cattle movements among farms), presence of cubicle housing, rough grazing areas (i.e., poor quality soil), and presence of European badgers on the farm [63]. Various farms practices can contribute to transmission of $M$. bovis through direct or indirect means (i.e., purchasing infected cattle from an outside source, use of silage clamps) that are often difficult to confirm definitively as being responsible for transmission of $M$. bovis. Cattle housed indoors rather than in pastures should be avoided to prevent within-herd transmission especially between cattle brought into a farm from an outside source to decrease chance of direct contact of infected cattle or deposition and subsequent survival of $M$. bovis in indoor facilities $[65,66]$.

The type of cattle operations (i.e., dairy, beef) posed different threats to transmission of $M$. bovis because the practices differ based on the product desired for the different operations. Mixed dairy and beef operations typically move cattle between operations more so than single dairy or beef operations to maintain adequate animals to meet production standards [76]. The increased risk of TB associated with movement of cattle onto farms from markets or farm sales seems logical and an outside source of TB infection has been documented for farms that have cattle positive for M. bovis in Canada, UK, Ireland, and US $[63,64,77,84]$.

Additional practices not included in WRMAP include landscape configuration and surrounding habitat types and additional wildlife activity on farms that have had cattle test positive for M. bovis. Mathews et al. [85] found a decreased risk of $M$. bovis in cattle herds on farms that practiced "nature friendly management" such as the presence of ungrazed wildlife strips and greater availability, width, and continuity of hedgerows. Although wildlife strips and hedgerows may be more important to disease transmission in European badgers, Kaneene et al. [13] documented a decrease in risk of $M$. bovis in cattle with an increase in the amount of open range on case-control farms in Michigan. Although the WRMAP addresses the proximity of livestock to "good deer habitat," additional details on habitat types and configuration may be necessary.

Surveillance of opossum and raccoon on farms that have had cattle test positive for $M$. bovis 2 years after depopulation of cattle found mammals, other than white-tailed deer, that were infected with M. bovis (D. Marks, Wildlife Services, unpublished data). Although shedding of $M$. bovis by opossum was not investigated, persistence of $M$. bovis on depopulated farms from environmental sources or survival of $M$. bovis in opossum for several years suggested that constant exposure to $M$. bovis was occurring. Research findings that rely on inoculation of a single dose $[37,38]$ or where animals were inoculated with multiple doses [39], may not mimic the proper infective dose or duration of exposure to $M$. bovis that is occurring in the natural environment. Where free-ranging mammals may be experiencing continuous or repeated exposures to infection over weeks or months should be a focus of future research. The conflicting results of research on medium-sized mammals, low sample sizes, inability of laboratory studies to mimic exposure to $M$. bovis in free-ranging animals, lack of research on shedding by free-ranging animals, and badgers as reservoirs in New Zealand and Europe suggest that more research on mediumsized mammals as reservoirs is warranted in North America.

\section{Summary}

The WRMAP created by the MDARD for use on farms in the upper lower peninsula of Michigan was designed following years of interviews, surveys, research, and anecdotal observations of deer on cattle farms in North America $[10,33,72]$. Combined with knowledge of badger use of farms in the UK and Ireland and brushtail possum in New Zealand, decreasing disease transmission through changed farm practices was a logical first step in eradicating $M$. bovis in Michigan. Since the hunter harvested deer was found with M. bovis in 1994, the ban on supplemental feeding of deer and reductions of deer herds has considerably reduced $M$. bovis prevalence in deer and on-farm risk mitigation programs have reduced the risk of farm breakdowns.

Regardless of the efforts of management agencies in Michigan, several cattle farms experience an M. bovis breakdown each year within and outside of Michigan's TB core area. Additional practices to prevent access by medium-sized mammals to stored feed and cattle feed troughs could be included in WRMAP. Although the ability of mammals other than deer to shed M. bovis in nasal and salivary secretions and excrement is not well documented in Michigan, mediumsized mammalian species are primary reservoirs of $M$. bovis in New Zealand and Europe. Reoccurrence of M. bovis on farms depopulated of cattle would suggest an environmental or mammalian host source of reinfection as several farms have become reinfected with $M$. bovis on $\geq 2$ separate occasions often spanning 3-7 years between re-infection. Assessing the potential for reservoirs other than white-tailed deer is necessary due to the current low prevalence of $M$. bovis in white-tailed deer. The low prevalence has resulted from the reduction in the number of deer, changing management priorities, and the very few direct and indirect interactions between white-tailed deer and cattle on farms in Michigan ([31, 86] National Wildlife Research Center, unpublished data). An understanding of the use of farms by Virginia opossum has been initiated but additional research on mediumsized mammals is needed in Michigan [87, 88].

Research has demonstrated considerable shedding of $M$. bovis by terminally ill free-ranging badgers and brushtail possum, but there have not been any similar observations in comparable-sized free-ranging mammals in Michigan. Surveillance for $M$. bovis infection in mesocarnivores in 
TABle 2: Surveillance studies identifying all species collected and analyzed that had cultures that were tested for Mycobacterium bovis in North America.

\begin{tabular}{|c|c|c|c|}
\hline \multirow{2}{*}{ Common name Scientific name } & \multicolumn{3}{|c|}{ Positive samples/total samples } \\
\hline & Witmer et al. [89] & O’Brien et al. [9] & Bruning-Fann et al. [5] \\
\hline Study dates & $2002-2004$ & $1996-2003$ & $1996-1999$ \\
\hline Black bear Ursus americanus & & $7 / 214$ & $1 / 42$ \\
\hline Badger Taxidea taxus & $0 / 4$ & $0 / 46$ & $0 / 2$ \\
\hline Beaver Castor canadensis & $0 / 61$ & NA & NA \\
\hline Bobcat Felis rufus & $0 / 3$ & $4 / 57$ & $0 / 8$ \\
\hline Coyote Canis latrans & $0 / 2$ & $18 / 375$ & $6 / 106$ \\
\hline Deer mouse Peromyscus maniculatus & $0 / 24$ & NA & NA \\
\hline Domestic cat Felis catus & $0 / 10$ & $0 / 35$ & NA \\
\hline Domestic dog Canis canis & NA & $0 / 1$ & NA \\
\hline Domestic rabbit Oryctolagus cuniculus & $0 / 1$ & NA & NA \\
\hline Eastern chipmunk Tamias striatus & $0 / 66$ & NA & NA \\
\hline Eastern cottontail Sylvilagus floridanus & $0 / 41$ & NA & NA \\
\hline E. gray squirrel Sciurus carolinensis & $0 / 26$ & NA & NA \\
\hline Eastern mole Scalopus aquaticus & $0 / 1$ & NA & NA \\
\hline Fox squirrel Sciurus niger & $0 / 17$ & NA & NA \\
\hline Gray fox Urocyon cinereoargenteus & $1 / 1$ & $0 / 5$ & $0 / 1$ \\
\hline House mouse Mus musculus & $0 / 62$ & NA & NA \\
\hline Long-tailed weasel Mustela frenata & NA & $0 / 1$ & NA \\
\hline Meadow jumping mouse Zapus hudsonius & $0 / 7$ & NA & NA \\
\hline Meadow vole Microtus pennsylvanicus & $0 / 77$ & NA & NA \\
\hline Mink Mustela vison & NA & $0 / 5$ & NA \\
\hline Muskrat Ondatra zibethicus & $0 / 5$ & NA & NA \\
\hline N. flying squirrel Glaucomys sabrinus & $0 / 1$ & NA & NA \\
\hline Porcupine Erethizon dorsatum & $0 / 71$ & $0 / 1$ & NA \\
\hline Raccoon Procyon lotor & $5 / 203$ & $8 / 333$ & $2 / 48$ \\
\hline Red fox Vulpes vulpes & NA & $3 / 29$ & $1 / 5$ \\
\hline Red squirrel Tamias striatus & $0 / 58$ & NA & NA \\
\hline Red-backed vole Clethrionomys gapperi & $0 / 3$ & NA & NA \\
\hline River otter Lutra canadensis & NA & $0 / 10$ & NA \\
\hline Snowshoe hare Lepus americanus & $0 / 23$ & $0 / 1$ & NA \\
\hline S. bog lemming Synaptomys cooperi & $0 / 1$ & NA & NA \\
\hline S. flying squirrel Glaucomys volans & $0 / 3$ & NA & NA \\
\hline Striped skunk Mephitis mephitis & $0 / 46$ & $0 / 21$ & NA \\
\hline 13-lined ground squirrel Spermophilus tridecemlineatus & $0 / 4$ & NA & NA \\
\hline Virginia opossum Didelphis virginianus & $4 / 135$ & $2 / 379$ & $0 / 54$ \\
\hline White-footed mouse Peromyscus leucopus & $0 / 66$ & NA & NA \\
\hline White-tailed deer Odocoileus virginianus & $0 / 2$ & NA & NA \\
\hline Woodchuck Marmota monax & $0 / 10$ & NA & NA \\
\hline Woodland vole Microtus pinetorum & $0 / 3$ & NA & NA \\
\hline
\end{tabular}

Michigan has found that numerous species may be spillover hosts (Table 2) but research on shedding by infected freeranging animals, other than white-tailed deer, has not been reported (but see [83]). Several wild animal species are known to use stored feed and farms buildings (e.g., barns, feed silos; $[31,87,89])$ so the potential for deposition of contaminated excreta is possible. Until additional research is conducted on potential reservoirs of $M$. bovis other than deer and more information is known on environmental persistence of M. bovis (e.g., in silage or grass clamps) in Michigan, the current WRMAP has provided sound guidance for onfarm mitigation of disease transmission. Requesting the 
assistance of farmers to protect stored feed, undertake appropriate feeding protocols, decrease cattle use of preferred deer habitat, and the banning of supplemental feeding of wild deer would the most appropriate initial steps to decrease $M$. bovis transmission should future outbreaks occur in previously TB-free states or provinces.

From the literature review, we have identified additional measures that can be added to the WRMAP. The data to justify their implementation may not be currently available to assess our suggestions, predominately the transport of cattle from farm to farm. Although strict regulations are in compliance for the most part, farmers would need to be completely forthcoming with that information in order to assess whether or not export or import of cattle within Michigan's TB core area is actually contributing to continued presence of the disease. The reduction in density and prevalence of $M$. bovis in deer, the primary wildlife reservoir in Michigan, and breakdowns on previously unaffected farms along with recurrent breakdown on previously infected farms would suggest that other sources of infection are still involved in transmission of $M$. bovis. The very low risk of breakdown (i.e., 1 farm per year) continues to make determining the source or sources of infection very problematic.

\section{Acknowledgments}

Funding for this project was provided by the Animal Industry Division of the Michigan Department of Agriculture and Rural Development and the USDA/APHIS/WS National Wildlife Research Center. Use of trade names does not imply endorsement by the federal government.

\section{References}

[1] S. M. Schmitt, S. D. Fitzgerald, T. M. Cooley et al., "Bovine tuberculosis in free-ranging white-tailed deer from Michigan," Journal of Wildlife Diseases, vol. 33, no. 4, pp. 749-758, 1997.

[2] R. S. Clifton-Hadley, J. W. Wilesmith, and F. A. Stuart, "Mycobacterium bovis in the European badger (Meles meles): epidemiological findings in tuberculous badgers from a naturally infected population," Epidemiology and Infection, vol. 111, no. 1, pp. 9-19, 1993.

[3] M. R. Hutchings and S. Harris, "Effects of farm management practices on cattle grazing behaviour and the potential for transmission of bovine tuberculosis from badgers to cattle," Veterinary Journal, vol. 153, no. 2, pp. 149-162, 1997.

[4] D. Ramsey, N. Spencer, P. Caley et al., "The effects of reducing population density on contact rates between brushtail possums: implications for transmission of bovine tuberculosis," Journal of Applied Ecology, vol. 39, no. 5, pp. 806-818, 2002.

[5] C. S. Bruning-Fann, S. M. Schmitt, S. D. Fitzgerald et al., "Bovine tuberculosis in free-ranging carnivores from Michigan," Journal of Wildlife Diseases, vol. 37, no. 1, pp. 58-64, 2001.

[6] D. J. O’Brien, S. M. Schmitt, D. E. Berry et al., "Estimating the true prevalence of Mycobacterium bovis in free-ranging elk in Michigan," Journal of Wildlife Diseases, vol. 44, no. 4, pp. 802 $810,2008$.

[7] M. S. Garner, Movement patterns and behavior at winter feeding and fall baiting stations in a population of white-tailed deer infected with bovine tuberculosis in the northeastern lower peninsula of Michigan [Ph.D. thesis], Michigan State University, East Lansing, Mich, USA, 2001.

[8] R. Miller, J. B. Kaneene, S. D. Fitzgerald, and S. M. Schmitt, "Evaluation of the influence of supplemental feeding of whitetailed deer (Odocoileus virginianus) on the prevalence of bovine tuberculosis in the Michigan wild deer population," Journal of Wildlife Diseases, vol. 39, no. 1, pp. 84-95, 2003.

[9] D. J. O’Brien, S. M. Schmitt, S. D. Fitzgerald, D. E. Berry, and G. J. Hickling, "Managing the wildlife reservoir of Mycobacterium bovis: the Michigan, USA, experience," Veterinary Microbiology, vol. 112, no. 2-4, pp. 313-323, 2006.

[10] M. Carstensen and M. W. DonCarlos, "Preventing the establishment of a wildlife disease reservoir: a case study of bovine tuberculosis in wild deer in Minnesota, USA," Veterinary Medicine International, vol. 2011, Article ID 413240, 10 pages, 2011.

[11] B. T. Garnett, R. J. Delahay, and T. J. Roper, "Use of cattle farm resources by badgers (Meles meles) and risk of bovine tuberculosis (Mycobacterium bovis) transmission to cattle," Proceedings of the Royal Society B, vol. 269, no. 1499, pp. 14871491, 2002.

[12] M. J. Daniels, M. R. Hutchings, and A. Greig, "The risk of disease transmission to livestock posed by contamination of farm stored feed by wildlife excreta," Epidemiology and Infection, vol. 130, no. 3, pp. 561-568, 2003.

[13] J. B. Kaneene, C. S. Bruning-Fann, L. M. Granger, R. Miller, and B. A. Porter-Spalding, "Environmental and farm management factors associated with tuberculosis on cattle farms in northeastern Michigan," Journal of the American Veterinary Medical Association, vol. 221, no. 6, pp. 837-842, 2002.

[14] C. C. Okafor, D. L. Grooms, C. S. Bruning-Fann, J. J. Averill, and J. B. Kaneene, "Descriptive epidemiology of bovine tuberculosis in Michigan (1975-2010): lessons learned," Veterinary Medicine International, vol. 2011, Article ID 874924, 13 pages, 2011.

[15] N. H. Smith, K. Kremer, J. Inwald et al., "Ecotypes of the Mycobacterium tuberculosis complex," Journal of Theoretical Biology, vol. 239, no. 2, pp. 220-225, 2006.

[16] L. A. L. Corner, D. U. Pfeiffer, G. W. De Lisle, R. S. Morris, and B. M. Buddle, "Natural transmission of Mycobacterium bovis infection in captive brushtail possums (Trichosurus vulpecula)," New Zealand Veterinary Journal, vol. 50, no. 4, pp. 154162, 2002.

[17] B. W. Gannon, C. M. Hayes, and J. M. Roe, "Survival rate of airborne Mycobacterium bovis," Research in Veterinary Science, vol. 82, no. 2, pp. 169-172, 2007.

[18] L. A. L. Corner, E. Costello, S. Lesellier, D. O'Meara, and E. Gormley, "Experimental tuberculosis in the European badger (Meles meles) after endobronchial inoculation with Mycobacterium bovis: II. progression of infection," Research in Veterinary Science, vol. 85, no. 3, pp. 481-490, 2008.

[19] D. W. Macdonald, B. J. Harmsen, P. J. Johnson, and C. Newman, "Increasing frequency of bite wounds with increasing population density in Eurasian badgers, Meles meles," Animal Behaviour, vol. 67, no. 4, pp. 745-751, 2004.

[20] L. A. L. Corner, D. Murphy, and E. Gormley, "Mycobacterium bovis Infection in the Eurasian Badger (Meles meles): the disease, pathogenesis, epidemiology and control," Journal of Comparative Pathology, vol. 144, no. 1, pp. 1-24, 2011.

[21] R Jackson, G. W. de Lisle, and R. S. Morris, "A study of the environmental survival of Mycobacterium bovis on a farm in New Zealand," New Zealand Veterinary Journal, vol. 43, no. 7, pp. 346-352, 1995. 
[22] M. V. Palmer, W. R. Waters, and D. L. Whipple, "Shared feed as a means of deer-to-deer transmission of Mycobacterium bovis," Journal of Wildlife Diseases, vol. 40, no. 1, pp. 87-91, 2004.

[23] M. V. Palmer, W. R. Waters, and D. L. Whipple, "Investigation of the transmission of Mycobacterium bovis from deer to cattle through indirect contact," American Journal of Veterinary Research, vol. 65, no. 11, pp. 1483-1489, 2004.

[24] L. A. L. Corner, E. Costello, S. Lesellier, D. O’Meara, D. P. Sleeman, and E. Gormley, "Experimental tuberculosis in the European badger (Meles meles) after endobronchial inoculation of Mycobacterium bovis: I. pathology and bacteriology," Research in Veterinary Science, vol. 83, no. 1, pp. 53-62, 2007.

[25] L. A. L. Corner, D. O'Meara, E. Costello, S. Lesellier, and E. Gormley, "The distribution of Mycobacterium bovis infection in naturally infected badgers," The Veterinary Journal. In press.

[26] L. A. Corner and P. J. A. Presidente, "Mycobacterium bovis infection in the brush-tailed possum (Trichosurus vulpecula): I. preliminary observations on experimental infection," Veterinary Microbiology, vol. 5, no. 4, pp. 309-321, 1980.

[27] B. M. Buddle, F. E. Aldwell, A. Pfeffer, and G. W. De Lisle, "Experimental Mycobacterium bovis infection in the brushtail possum (Trichosurus vulpecula): pathology, haematology and lymphocyte stimulation responses," Veterinary Microbiology, vol. 38, no. 3, pp. 241-254, 1994.

[28] United States Department of Agriculture, Assessment of Pathways for the Introduction and Spread of Mycobacterium bovis in the United States, USDA-APHIS-VS-CEAH, Fort Collins, Colo, USA, 2009.

[29] J. Rhyan, K. Aune, B. Hood et al., "Bovine tuberculosis in a free-ranging mule deer (Odocoileus hemionus) from Montana," Journal of Wildlife Diseases, vol. 31, no. 3, pp. 432-435, 1995.

[30] K. C. Vercauteren, M. J. Lavelle, N. W. Seward, J. W. Fischer, and G. E. Phillips, "Fence-line contact between wild and farmed white-tailed deer in Michigan: potential for disease transmission," Journal of Wildlife Management, vol. 71, no. 5, pp. 1603-1606, 2007.

[31] J. A. Hill, Wildlife-cattle interactions in northern Michigan: implications for the transmission of bovine tuberculosis [Ph.D. thesis], Utah State University, Logan, Utah, USA, 2005.

[32] R. K. Brook and S. M. McLachlan, "Transdisciplinary habitat models for elk and cattle as a proxy for bovine tuberculosis transmission risk," Preventive Veterinary Medicine, vol. 91, no. 2-4, pp. 197-208, 2009.

[33] R. K. Brook, "Incorporating farmer observations in efforts to manage bovine tuberculosis using barrier fencing at the wildlife-livestock interface," Preventive Veterinary Medicine, vol. 94, no. 3-4, pp. 301-305, 2010.

[34] K. L. Butler, S. D. Fitzgerald, D. E. Berry, S. V. Church, W. M. Reed, and J. B. Kaneene, "Experimental inoculation of European starlings (Sturnus vulgaris) and American crows (Corvus brachyrhynchos) with Mycobacterium bovis," Avian Diseases, vol. 45, no. 3, pp. 709-718, 2001.

[35] S. D. Fitzgerald, K. G. Boland, K. R. Clarke et al., "Resistance of mallard ducks (Anas platyrhynchos) to experimental inoculation with Mycobacterium bovis," Avian Diseases, vol. 49, no. 1, pp. 144-146, 2005.

[36] S. D. Fitzgerald, L. S. Zwick, D. E. Berry, S. V. Church, J. B. Kaneene, and W. M. Reed, "Experimental inoculation of pigeons (Columba livia) with Mycobacterium bovis," Avian Diseases, vol. 47, no. 2, pp. 470-475, 2003.

[37] K. L. Diegel, S. D. Fitzgerald, D. E. Berry et al., "Experimental inoculation of North American opossums (Didelphis virginiana) with Mycobacterium bovis," Journal of Wildlife Diseases, vol. 38, no. 2, pp. 275-281, 2002.
[38] S. D. Fitzgerald, L. S. Zwick, K. L. Diegel et al., "Experimental aerosol inoculation of Mycobacterium bovis in North American opossums (Didelphis virginiana)," Journal of Wildlife Diseases, vol. 39, no. 2, pp. 418-423, 2003.

[39] M. V. Palmer, W. R. Waters, and D. L. Whipple, "Susceptibility of raccoons (Procyon lotor) to infection with Mycobacterium bovis," Journal of Wildlife Diseases, vol. 38, no. 2, pp. 266-274, 2002.

[40] K. A. R. Clarke, S. D. Fitzgerald, L. S. Zwick et al., "Experimental inoculation of meadow voles (Microtus pennsylvanicus), house mice (Mus musculus), and Norway rats (Rattus norvegicus) with Mycobacterium bovis," Journal of Wildlife Diseases, vol. 43, no. 3, pp. 353-365, 2007.

[41] T. W. A. Little, P. F. Naylor, and J. W. Wilesmith, "Laboratory study of Mycobacterium bovis infection in badgers and calves," Veterinary Record, vol. 111, no. 24, pp. 550-557, 1982.

[42] M. A. Chambers, W. A. Pressling, C. L. Cheeseman, R. S. Clifton-Hadley, and R. G. Hewinson, "Value of existing serological tests for identifying badgers that shed Mycobacterium bovis," Veterinary Microbiology, vol. 86, no. 3, pp. 183-189, 2002.

[43] I. W. Lugton, G. Wobeser, R. S. Morris, and P. Caley, "Epidemiology of Mycobacterium bovis infection in feral ferrets (Mustela furo) in New Zealand: II. routes of infection and excretion," New Zealand Veterinary Journal, vol. 45, no. 4, pp. 151-157, 1997.

[44] D. R. Marks, United States Department of Agriculture, Animal and Plant Health Inspection Services, Wildlife Services, Okemos, Meridian Charter Township, MI, USA, Unpublished data.

[45] A. R. Berentsen, M. R. Dunbar, S. R. Johnson, S. RobbeAusterman, L. Martinez, and R. L. Jones, "Active use of coyotes (Canis latrans) to detect Bovine Tuberculosis in northeastern Michigan, USA," Veterinary Microbiology, vol. 151, no. 1-2, pp. 126-132, 2011.

[46] I. W. Lugton, P. R. Wilson, R. S. Morris, and G. Nugent, "Epidemiology and pathogenesis of Mycobacterium bovis infection of red deer (Cervus elaphus) in New Zealand," New Zealand Veterinary Journal, vol. 46, no. 4, pp. 147-156, 1998.

[47] J. O. Luna, M. A. A. Santos, E. L. Durigon, J. P. Araújo, and J. M. B. Duarte, "Tuberculosis survey of free-ranging marsh deer (Blastocerus dichotomus) in Brazil," Journal of Zoo and Wildlife Medicine, vol. 34, no. 4, pp. 414-415, 2003.

[48] M. V. Palmer, D. L. Whipple, and S. C. Olsen, "Development of a model of natural infection with Mycobacterium bovis in white-tailed deer," Journal of Wildlife Diseases, vol. 35, no. 3, pp. 450-457, 1999.

[49] M. V. Palmer, D. L. Whipple, and W. R. Waters, "Experimental deer-to-deer transmission of Mycobacterium bovis," American Journal of Veterinary Research, vol. 62, no. 5, pp. 692-696, 2001.

[50] T. McCorry, A. O. Whelan, M. D. Welsh et al., "Shedding of Mycobacterium bovis in the nasal mucus of cattle infected experimentally with tuberculosis by the intranasal and intratracheal routes," Veterinary Record, vol. 157, no. 20, pp. 613618, 2005.

[51] R. S. Williams and W. A. Hoy, "The viability of B. tuberculosis (bovinus) on pasture land, in stored faeces and in liquid manure," Journal of Wildife Diseases, vol. 30, no. 4, pp. 413419, 1930.

[52] E. C. G. Maddock, "Studies on the survival time of the bovine tubercle bacillus in soil, soil and dung, in dung and on grass, with experiments on the preliminary treatment of infected organic matter and the cultivation of the organism," Journal of Hygeine, vol. 33, no. 1, pp. 103-117, 1933. 
[53] E. C. G. Maddock, "Further studies on the survival time of the bovine tubercle bacillus in soil, soil and dung, in dung and on grass, with experiments on feeding guinea-pigs and calves on grass artificially infected with bovine tubercle bacilli," Journal of Hygeine, vol. 34, no. 3, pp. 372-379, 1934.

[54] D. J. Van Donsel and E. P. Larkin, "Persistence of Mycobacterium bovis BCG in soil and on vegetables spray-irrigated with sewage effluent and sludge," Journal of Food Protection, vol. 40, no. 3, pp. 160-163, 1977.

[55] B. J. Duffield and D. A. Young, "Survival of Mycobacterium bovis in defined environmental conditions," Veterinary Microbiology, vol. 10, no. 2, pp. 193-197, 1984.

[56] J. S. Young, E. Gormley, and E. M. H. Wellington, "Molecular detection of Mycobacterium bovis and Mycobacterium bovis BCG (Pasteur) in soil," Applied and Environmental Microbiology, vol. 71, no. 4, pp. 1946-1952, 2005.

[57] M. Tanner and A. L. Michel, "Investigation of the viability of $M$. bovis under different environmental conditions in the Kruger National Park," Onderstepoort Journal of Veterinary Research, vol. 66, no. 3, pp. 185-190, 1999.

[58] M. V. Palmer and D. L. Whipple, "Survival of Mycobacterium bovis on feedstuffs commonly used as supplemental feed for white-tailed deer (Odocoileus virginianus)," Journal of Wildlife Diseases, vol. 42, no. 4, pp. 853-858, 2006.

[59] A. E. Fine, C. A. Bolin, J. C. Gardiner, and J. B. Kaneene, "A study of the persistence of Mycobacterium bovis in the environment under natural weather conditions in Michigan, USA," Veterinary Medicine International, vol. 2011, Article ID 765430, 12 pages, 2011.

[60] C. F. Briscoe, "Fate of tubercle bacilli outside the animal body," Illinois Agricultural Experimental Station Bulletin 161, Urbana, Ill, USA, 1912.

[61] A. L. Michel, L. M. De Klerk, N. C. G. Van Pittius, R. M. Warren, and P. D. Van Helden, "Bovine tuberculosis in African buffaloes: observations regarding Mycobacterium bovis shedding into water and exposure to environmental mycobacteria," BMC Veterinary Research, vol. 3, article no. 23, 2007.

[62] D. L. Whipple and M. V. Palmer, "Survival of Mycobacterium bovis on feeds," in Proceedings of the Bovine Tuberculosis Conference, vol. 4, p. 18, August 2000.

[63] J. M. Griffin, T. Hahesy, K. Lynch, M. D. Salman, J. McCarthy, and T. Hurley, "The association of cattle husbandry practices, environmental factors and farmer characteristics with the occurence of chronic bovine tuberculosis in dairy herds in the Republic of Ireland," Preventive Veterinary Medicine, vol. 17, no. 3-4, pp. 145-160, 1993.

[64] L. A. Reilly and O. Courtenay, "Husbandry practices, badger sett density and habitat composition as risk factors for transient and persistent bovine tuberculosis on UK cattle farms," Preventive Veterinary Medicine, vol. 80, no. 2-3, pp. 129-142, 2007.

[65] C. J. C. Phillips, C. R. W. Foster, P. A. Morris, and R. Teverson, "The transmission of Mycobacterium bovis infection to cattle," Research in Veterinary Science, vol. 74, no. 1, pp. 1-15, 2003.

[66] L. M. O'Reilly and C. J. Daborn, “The epidemiology of Mycobacterium bovis infections in animals and man: a review," Tubercle and Lung Disease, vol. 76, supplement 1, pp. 1-46, 1995.

[67] A. F. Cunningham and C. L. Spreadbury, "Mycobacterial stationary phase induced by low oxygen tension: cell wall thickening and localization of the 16-kilodalton $\alpha$-crystallin homolog," Journal of Bacteriology, vol. 180, no. 4, pp. 801-808, 1998.

[68] B. Hutter and T. Dick, "Increased alanine dehydrogenase activity during dormancy in Mycobacterium smegmatis," FEMS Microbiology Letters, vol. 167, no. 1, pp. 7-11, 1998.
[69] A. Lim, M. Eleuterio, B. Hutter, B. Murugasu-Oei, and T. Dick, "Oxygen depletion-induced dormancy in Mycobacterium bovis BCG," Journal of Bacteriology, vol. 181, no. 7, pp. 2252-2256, 1999.

[70] A. G. Williams, R. P. Hoxey, and J. F. Lowe, "Changes in temperature and silo gas composition during ensiling, storage and feeding-out grass silage," Grass and Forage Science, vol. 52, no. 2, pp. 176-189, 1997.

[71] E. Mitscherlich and E. H. Marth, Microbial Survival in the Environment: Bacteria and Rickettsiae Important in Human and Animal Health, Springer, Berlin, Germany, 1984.

[72] B. Knust, Reducing the public health impact of bovine tuberculosis by controlling disease trasmission between cattle and whitetailed deer in Northwestern Minnesota [Ph.D. thesis], University of Minnesota, Minneapolis, Minn, USA, 2008.

[73] A. E. Fine, The role of indirect transmission in the epidemiology of bovine tuberculosis in cattle and white-tailed deer in Michigan [Ph.D. thesis], Michigan State University, East Lansing, Mich, USA, 2006.

[74] A. R. Berentsen, R. S. Miller, M. R. Dunbar, and R. Misiewicz, "Farm visitation by white-tailed deer (Odocoileus virginianus) in northeastern michigan, USA: implications for bovine tuberculosis transmission," in Proceedings of the 5th International $M$. Bovis Conference, Wellington, New Zealand, 2009.

[75] B. M. Paterson, R. S. Morris, J. Weston, and P. E. Cowan, "Foraging and denning patterns of brushtail possums, and their possible relationship to contact with cattle and the transmission of bovine tuberculosis," New Zealand Veterinary Journal, vol. 43, no. 7, pp. 281-288, 1995.

[76] S. Marangon, M. Martini, M. D. Dalla Pozza, and J. F. Neto, "A case-control study on bovine tuberculosis in the Veneto Region (Italy)," Preventive Veterinary Medicine, vol. 34, no. 23, pp. 87-95, 1998.

[77] W. T. Johnston, G. Gettinby, D. R. Cox et al., "Herd-level risk factors associated with tuberculosis breakdowns among cattle herds in England before the 2001 foot-and-mouth disease epidemic," Biology Letters, vol. 1, no. 1, pp. 53-56, 2005.

[78] G. Mcdonnell and A. D. Russell, "Antiseptics and disinfectants: activity, action, and resistance," Clinical Microbiology Reviews, vol. 12, no. 1, pp. 147-179, 1999.

[79] M. P. Scanlon and P. J. Quinn, "Inactivation of Mycobacterium bovis in cattle slurry by five volatile chemicals," Journal of Applied Microbiology, vol. 89, no. 5, pp. 854-861, 2000.

[80] M. J. M. Vaerewijck, G. Huys, J. C. Palomino, J. Swings, and F. Portaels, "Mycobacteria in drinking water distribution systems: ecology and significance for human health," FEMS Microbiology Reviews, vol. 29, no. 5, pp. 911-934, 2005.

[81] B. M. Knust, P. C. Wolf, and S. J. Wells, "Characterization of the risk of deer-cattle interactions in Minnesota by use of an on-farm environmental assessment tool," American Journal of Veterinary Research, vol. 72, no. 7, pp. 924-931, 2011.

[82] J. M. Griffin, D. H. Williams, G. E. Kelly et al., "The impact of badger removal on the control of tuberculosis in cattle herds in Ireland," Preventive Veterinary Medicine, vol. 67, no. 4, pp. 237-266, 2005.

[83] State of Michigan, 2008, Proceedings of the Michigan Bovine Tuberculosis Eradication Project Activities Report.

[84] V. W. Lees, "Learning from outbreaks of bovine tuberculosis near Riding Mountain National Park: applications to a foreign animal disease outbreak," Canadian Veterinary Journal, vol. 45, no. 1, pp. 28-34, 2004.

[85] F. Mathews, L. Lovett, S. Rushton, and D. W. Macdonald, "Bovine tuberculosis in cattle: reduced risk on wildlifefriendly farms," Biology Letters, vol. 2, no. 2, pp. 271-274, 2006. 
[86] B. A. Rudolph, S. J. Riley, G. J. Hickling, B. J. Frawley, M. S. Garner, and S. R. Winterstein, "Regulating hunter baiting for white-tailed deer in Michigan: biological and social considerations," Wildlife Society Bulletin, vol. 34, no. 2, pp. 314321, 2006.

[87] T. C. Atwood, T. J. Deliberto, H. J. Smith, J. S. Stevenson, and K. C. Vercauteren, "Spatial ecology of raccoons related to cattle and bovine tuberculosis in Northeastern Michigan," Journal of Wildlife Management, vol. 73, no. 5, pp. 647-654, 2009.

[88] W. D. Walter, United States Department of Agriculture, Animal and Plant Health Inspection Services, Wildlife Services, National Wildlife Research Center, Fort Collins, Colo, USA, Unpublished data.

[89] G. Witmer, A. E. Fine, J. Glonfriddo et al., "Epizootiologic survey of Mycobacterium bovis in wildlife and farm environments in northern michigan," Journal of Wildlife Diseases, vol. 46, no. 2, pp. 368-378, 2010.

[90] J. Gallagher, R. Monies, M. Gavier-Widen, and B. Rule, "Role of infected, non-diseased badgers in the pathogenesis of tuberculosis in the badger," Veterinary Record, vol. 142, no. 26, pp. 710-714, 1998. 

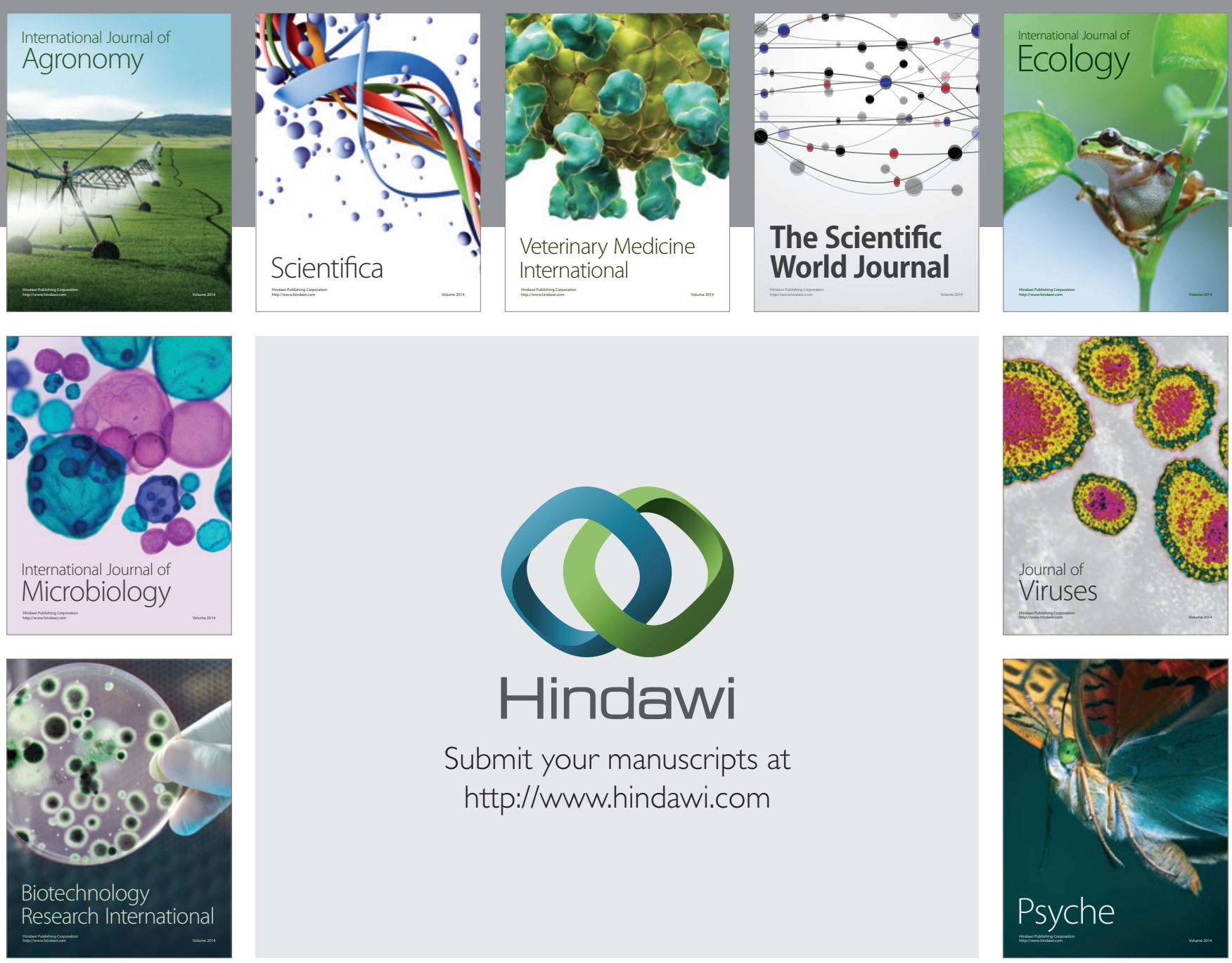

Submit your manuscripts at

http://www.hindawi.com
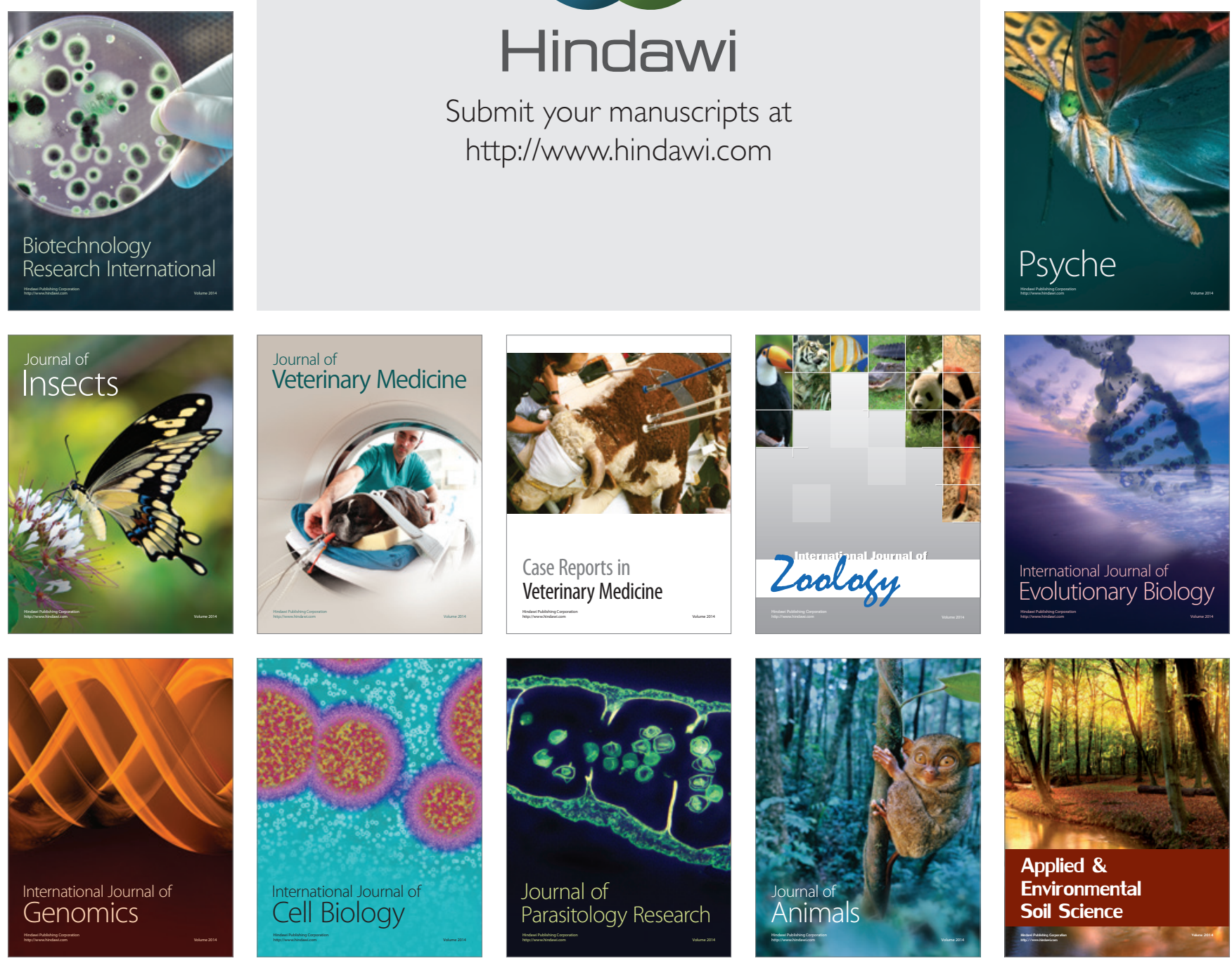